Relato de Experiência Profissional 



\title{
ENFRENTAMENTo À ViolêNCIA CONTRA CRIANÇAS E adolescentes: Projeto Escola Que Protege ${ }^{\star}$
}

\author{
Rosângela Francischini $i^{\star \star}$ \\ Manoel Onofre de Souza Neto ${ }^{\star \star \star}$
}

\begin{abstract}
Resumo
O Estatuto da Criança e do Adolescente especifica que toda criança deverá estar protegida de ações que possam prejudicar seu desenvolvimento. No entanto, a realidade de transgressão a esse direito atinge uma parcela significativa de crianças, que têm seu cotidiano permeado por variadas formas de violência. Como objetivo de formar profissionais em educação para atuar na defesa dos direitos desses sujeitos a SECAD/MEC, implantou o Projeto Escola que Protege, objeto desta apresentação, considerando que a definição de uma política eficiente no enfretamento da violência passa pelo envolvimento de diversos e estratégicos atores sociais, dentre eles, a comunidade escolar.
\end{abstract}

Palavras Chave: Violência. Crianças. Adolescentes. Direitos.

\begin{abstract}
The Child and Adolescent Statute specifies that every child has the right to be protected against actions that may hamper her development. The transgression of this Right affects a significant portion of children, which have their quotidian permeated by various forms of violence. With the purpose of preparing professionals in Education to work in defending the rights of children and adolescents that are violence victims, the SECAD/MEC implemented the project Escola que Protege (School that Protects), the main focus of this presentation. It is important to consider that the definition of an efficient policy that confronts violence involves the work of various strategic social actors, among them, the school community.
\end{abstract}

Key words: Violence. Children. Adolescents. Rights.

* Projeto Financiado pela Secretaria de Educação Continuada, Alfabetização e Diversidade, do Ministério da Educação, e pelo Instituto Companheiros das Américas/Partners of the Américas.

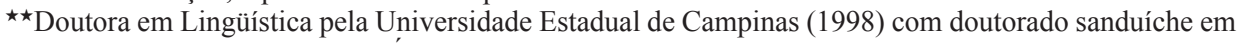
Psychologie et Sciences de 1'Éducation - Université de Genève (1998). Atualmente é professora do Departamento de Psicologia - graduação e pós-graduação - da Universidade Federal do Rio Grande do Norte, coordenadora do Núcleo de Estudos Sócio-Culturais da Infância e Adolescência CCHLA. Endereço: Rua Ismael Pereira da Silva, 1733/202, Bairro Capim Macio. CEP 59082000 - Natal/RN. E-mail:rfranci@uol.com.br

${ }^{\star \star \star}$ Promotor de Justiça da Capital do Ministério Público do Estado do Rio Grande do Norte. Coordenador do Centro de Apoio Operacional às Promotorias de Defesa da Infância e da Juventude do Rio Grande do Norte-CAOPIJ/RN.

E-mail: manoelonofre@yahoo.com.br 


\section{A VIOLÊNCIA CONTRA CRIANÇAS - A REALIDADE TORNADA VISÍVEL}

Recentemente, foi entregue à Organização das Nações Unidas (ONU) um Relatório (daqui em diante: Relatório do UNICEF) que retrata a condição da violência contra crianças, resultado de uma investigação ${ }^{1}$ aprofundada sobre o tema, realizada pelo especialista Prof. Paulo Sérgio Pinheiro, diretor do Núcleo de Estudos da Violência, da Universidade de São Paulo (USP).

Trata-se do primeiro estudo com essa abrangência e dimensão realizado até então, e teve como objetivo traçar um panorama detalhado sobre a natureza, o alcance e as causas da violência contra crianças e adolescentes, além de apresentar algumas recomendações para impedir que essa violação dos Direitos Humanos continue tendo lugar no tratamento a essa parcela da população e para enfrentar aquelas formas de violência que estão estabelecidas nas sociedades, seja por permissão do Estado, seja por estarem enraizadas nas comunidades, seja como método disciplinar.

De acordo com o Relatório:

El Estudio llega a la conclusión de que la violencia contra la infancia tiene lugar en todos los lugares, en todos los países y sociedades y afecta a todos los grupos sociales. La violencia extrema contra ellos puede convertirse en un titular de los medios de comunicación, pero los niños afirman que los pequeños y reiterados actos de violencia y malos tratos que sufren a diario también les hacen daño. Si bien parte de esta violencia es inesperada y aislada, la mayor parte de los actos violentos contra niños y niñas los llevan a cabo personas que ellos conocen y en las que deberían poder confiar: progenitores, novios o novias, consortes y parejas, compañeros de escuela, maestros y patronos. La violencia contra la infancia incluye violencia física, violencia psicológica como insultos y humillaciones, discriminación, abandono y malos tratos. Aunque las consecuencias pueden variar según la naturaleza y gravedad de la violencia infligida, las repercusiones a corto y largo plazo para los niños y niñas, y para el conjunto de la sociedad, suelen ser graves y perjudiciales. (ONU, 2006)

O estudo comprovou, ainda, que a violência contra crianças ocorre no lar e na família, nas escolas e outros ambientes educacionais, em sistemas assistenciais e de justiça, nos locais de trabalho e na comunidade, de um modo geral.

Segundo Minayo (2001, p. 26),

a violência contra crianças e adolescentes é todo ato ou omissão cometido pelos pais, parentes, outras pessoas e instituições capazes de causar dano físico, sexual e/ou psicológico à vítima. Implica, de um lado, uma transgressão no poder/dever de proteção do adulto e da sociedade em geral e, de outro, numa coisificação da infância. Isto é, uma negação do direito que crianças e adolescentes têm de serem tratados como sujeitos e pessoas em condições especiais de desenvolvimento. 
A prática de violência contra crianças e adolescentes (maus tratos, abandono e negligência, abuso e exploração sexual comercial, trabalho infantil, dentre outras) não é recente. Um olhar atento à trajetória histórica de crianças pobres no Brasil nos mostra a procedência dessa afirmação. Sua visibilidade, no entanto, vem ganhando novos contornos, principalmente, na proporção e extensão que vem ocorrendo nas duas últimas décadas, no Brasil. A promulgação do ECA, com certeza, contribuiu e vem contribuindo para que se torne visível uma condição, antes de tudo, de violação dos Direitos Humanos, conforme Declaração Universal dos Direitos Humanos, da ONU.

Vários são os fatores que contribuem para que essa prática seja observada e mantida, dentre os quais destacamos: as relações de poder e de gênero predominantes nas sociedades, as características do agressor e da vítima, questões culturais, ausência de mecanismos seguros e confiáveis, medo de denunciar, ineficiência dos órgãos de atendimento, certeza de impunidade, dentre outras.

Em relação à violência que ocupa lugar no interior das famílias, o Projeto Escola que Protege discute as relações de parentesco que existem entre o agressor e o sujeito violentado, o espaço físico em que essas violações ocorrem e as justificativas que mais comparecem nas pesquisas, qual seja, o uso da violência como "medida educativa". Em pesquisa anterior (FRANCISCHINI, 2003) procuramos identificar como as crianças vítimas de violência física intrafamiliar justificam as atitudes de seus cuidadores; a autoridade dos pais e a violência como forma de educação estiveram presentes nos discursos das crianças.

A violência praticada nas instituições educacionais de modo geral também comparece com muita freqüência nas estatísticas. Segundo o Relatório do UNICEF:

numa análise de uma ampla gama de países em desenvolvimento, a Pesquisa Global de Saúde Baseada na Escola verificou recentemente que de 20 a 65 por cento das crianças em idade escolar entrevistadas relataram terem sido verbal ou fisicamente intimidadas nos 30 dias anteriores" nesses espaços. (ONU, 2006)

Os dados constantes no mesmo relatório, relacionados ao abuso e violência sexual não são menos alarmantes. Senão, vejamos: "A OMS estima que 150 milhões de meninas e 73 milhões de meninos abaixo de 18 anos foram forçados a manter relações sexuais ou sofreram outras formas de violência sexual que envolveram contato físico em 2002.” (ONU, 2006).

A exploração do trabalho infantil ou exploração econômica, segundo o livro texto do Projeto objeto deste estudo, ocorre "quando crianças e adolescentes são constrangidos, convencidos ou obrigados a exercer funções e a assumir responsabilidades de adulto, inapropriadas à etapa de desenvolvimento em que se encontram". (FALEIROS; FALEIROS, 2006, p. 89) É importante observar que esta (e as demais) formas de violência dificilmente ocorrem de forma isolada. 
Neste contexto de discussão insere-se o presente trabalho, resultado de nossa participação no Projeto Escola que Protege, que teve como objetivo:

formar profissionais para atuar na defesa dos direitos de crianças e adolescentes em situações de violência física, psicológica negligência, abandono, abuso sexual, exploração do trabalho infantil, exploração sexual comercial e tráfico para esses fins, em uma perspectiva preventiva. (FALEIROS; FALEIROS, 2006, p. 17)

\section{O Ministério da Educação e o Projeto Escola que Protege: PROPOSTAS E IMPLEMENTAÇÃO}

Conforme explicitado anteriormente, o referido projeto é uma promoção da SECAD/MEC, em parceria técnica com o Instituto Partners of the Américas e com coordenação local das pró-reitorias de Extensão Universitária das instituições públicas federais de ensino superior, cuja função foi de organizar e realizar o módulo presencial, uma vez que houve módulo à distância e ensino presencial.

No módulo à distância, além do kit didático - livro texto (FALEIROS; FALEIROS, 2006) e videoaula em VHS -, os professores tiveram acesso a cinco sessões de teleconferência. Puderam contar, ainda, com um sistema de acompanhamento ao estudante, através de telefones, com a participação de tutores e monitores qualificados para esse propósito pela UFSC, e com um ambiente virtual de aprendizagem.

Com a conclusão do módulo presencial os coordenadores locais reuniramse, a convite da SECAD, em Brasília, em agosto de 2006. Naquela ocasião, na UFRN estávamos em processo de composição do módulo presencial. Portanto, os debates e as trocas de experiências proporcionadas no encontro foram de extrema relevância para todos. Apesar das necessidades específicas, determinadas pelas condições regionais, houve consenso em termos de temas que deveriam comparecer nos conteúdos programáticos desse módulo.

O módulo presencial ocorreu entre setembro e dezembro/2006, considerando as particularidades das instituições, suas necessidades e condições de implementação. Em dezembro, novamente os coordenadores reuniram-se no $\mathrm{Se}$ minário Diferentes Diferenças, promovido, igualmente pela SECAD. Não houve possibilidades de definição da seqüência ou não do Projeto uma vez que o país passou por um processo eleitoral para Presidência da República e, conforme previsto, um novo mandato implica em novos arranjos políticos, novas definições de ocupantes dos cargos públicos, como é o caso do Ministro da Educação e das Secretarias a ele vinculadas. 


\section{O Projeto Escola que Protege em nível local: a Realidade do municí́lio de Natal}

Seguindo orientação da SECAD, inicialmente, a Pró-Reitoria de Extensão convocou as Secretarias de Educação - Estadual e Municipal, um representante do Conselho Tutelar - Zona Leste, um representante de cada um dos Conselhos de Direitos da Criança e do Adolescente (Municipal e Estadual) e um representante do Ministério Público, especificamente da Promotoria da Infância e Juventude. Procurou-se, nesses encontros iniciais, sensibilizar esses organismos visando que os mesmos assumissem a estruturação do projeto, em nível local. Constituiu-se, desta forma, a Comissão Gestora, sob coordenação da Pró-Reitora de Extensão, com função de "Organizar o processo de inserção do sistema de educação no conjunto das ações de enfrentamento à violência contra crianças e adolescentes e estreitar as relações com as redes locais de atenção, defesa e responsabilização" (BRASIL, 2006, p. 2). Em momento posterior agreguei-me a esta comissão e assumi a coordenação do módulo presencial do curso.

Sob responsabilidade das Secretarias de Educação ficaram os processos de seleção e definição dos professores que iriam fazer parte da formação proposta e o acompanhamento e organização de infra-estrutura para realização do módulo à distância.

Com a proximidade da conclusão do Módulo à distância, a Comissão Gestora local passou, então, a se reunir para definição do módulo presencial. Decidiu-se, então, que o curso teria duração de 20 horas de atividades, a serem distribuídas em três dias consecutivos, em duas turmas. Observamos que na $2^{\mathrm{a}}$. turma, além dos professores das redes de ensino, participaram cinco alunos do curso de graduação em Psicologia/UFRN, membros do Núcleo de Estudos Sócio-Culturais da Infância e Adolescência. As atividades aconteceram em dependências da Universidade Federal do Rio Grande do Norte, mais especificamente, no imóvel onde funciona a Escola de Governo.

Foram selecionados, inicialmente, 102 educadores. No entanto, freqüentaram o curso 58 deles; 63, ao todo, considerando-se os cinco alunos do curso de Psicologia. Segundo os educadores presentes houve uma desistência significativa ainda por ocasião do módulo à distância. Além disso, muitos participantes não realizaram a atividade final prevista no mesmo. Deixaram, desta forma, de freqüentar o presencial. Essa condição coincide com as informações fornecidas em Brasília, em agosto/06, quando da reunião técnica com os coordenadores locais.

Em uma avaliação preliminar feita pela coordenação do módulo à distância divulgadas em agosto, em Brasília, na reunião dos Coordenadores, foram observados vários problemas, que necessitam ser revistos caso haja continuidade do Projeto, dentre os quais destacamos: freqüência entre 30 a $40 \%$ de educadores nas transmissões das teleconferências; comunicação não eficiente entre coordenação do módulo à distância e os representantes das Secretarias de Educação e/ou entre os monitores/tutores e os educadores; dificuldades de acesso aos recursos tecnológicos mínimos para o andamento do curso, não recebimento do material do curso em tempo hábil, divulgação e inscrição ineficientes. 
Na mesma reunião a que fizemos referência no parágrafo anterior, vários coordenadores reconheceram as mesmas dificuldades nele apontadas, acrescentando, ainda, outras, com destaque para a ausência de uma cultura de educação à distância e as conseqüentes dificuldades dela oriunda. Em seu conjunto, essas dificuldades levaram-nos, enquanto coordenadores, à conclusão de que o módulo à distância não alcançou os objetivos previstos.

Decorrentes da condição que se configurou, ampliou-se a responsabilidade do Módulo Presencial no sentido de que recaiu sobre ele o preenchimento das falhas observadas no módulo anterior.

Nas condições explicitadas acima, a Comissão Gestora local definiu o seguinte conteúdo programático a ser discutido no Módulo Presencial: Infância e Adolescência no Brasil: aspectos legais e sociais; A Rede de Proteção à Criança e ao Adolescente no Município; Principais Modalidades de Violência contra a criança: violência intra familiar; exploração do trabalho infanto-juvenil; abuso e exploração sexual comercial; Identificando crianças e adolescentes vítimas da violência: indicadores físicos, comportamentais e psicológicos; As atribuições da Vara da Infância e Juventude; A Escola e a crianças e adolescentes vítimas de violência: identificação, abordagem, notificação e encaminhamentos; A Ética na abordagem desse problema; Formulário de Notificação ao Conselho Tutelar.

Esses conteúdos foram distribuídos em "módulos" de 2 horas aulas para cada ministrante, de acordo com as atribuições de cada um nos organismos do sistema de garantia de direitos que eles representam. Assim, participaram representantes dos seguintes organismos: Núcleo de Estudos Sócio-Culturais da Infância e Adolescência (UFRN); Conselho Tutelar da Criança e do Adolescente - Zona Leste; Conselho Municipal dos Direitos da Criança e do Adolescente; Conselho Estadual dos Direitos da Criança e do Adolescente e Casa Renascer; Promotoria de Justiça da Infância e da Juventude; $1^{\text {a }}$. Vara da Infância e Juventude de Natal/ RN; FARN/RN.

Ao término de cada uma das turmas houve a apresentação, com participação dos educadores, de uma peça de teatro, organizada pelo grupo de Teatro da UFRN, que representou uma situação de violência física intrafamiliar contra uma criança e direcionou o roteiro no sentido de identificação, abordagem, notificação e encaminhamento do caso ao Conselho Tutelar, por parte da instituição escolar.

Ainda seguindo orientação da SECAD foi produzido e/ou distribuído aos educadores material de divulgação e didático, conforme especificação a seguir: Folder, (conteúdo programático, professores e cronograma das atividades); Apostila, com textos utilizados pelos professores ministrantes; três exemplares do ECA para cada professor, cedidos pela $1^{\text {a }}$. Vara da Infância e Juventude e pelo Conselho Estadual de Direitos da Criança e do Adolescente; Vídeo - com entrevistas da Pró-Reitora de Extensão, com a coordenadora do módulo presencial e com uma aluna do curso, "Kit didático": fita em VHS, com uma aula explicativa do projeto e um livro texto. 
Por fim, foram realizadas avaliações do Curso com os educadores/alunos onde se explicitou, por escrito, os aspectos positivos e negativos do mesmo, e a própria experiência de ter participado do processo. A leitura desse material deuse a partir da perspectiva da Análise de Conteúdo Temática (MINAYO, 2000) a partir da qual foram identificadas as unidades de significação que mais compareceram nos discursos dos alunos. Assim, temos, dentre os aspectos positivos, o conteúdo programático do curso, a equipe de professores ministrantes, a possibilidade de conhecimento da rede de Proteção e do ECA, desconhecidos, até então, para a grande maioria dos educadores, a possibilidade que o curso proporcionou de fornecer subsídios para identificação, abordagem, notificação e encaminhamento de crianças e adolescentes vítimas de violência e a importância da escola diante da condição de violação dos direitos de crianças e adolescentes e a organização do Curso.

Dentre os aspectos negativos, temos: o módulo à distância, a precariedade das comunicações entre as Secretarias de Educação e os Professores, a limitação do $\mathrm{n}^{\circ}$. de escolas e de professores participantes.

Os educadores apontaram, ainda, a necessidade de continuidade do curso em dois sentidos: ampliação do conteúdo e, consequentemente, da carga horária, ampliação da abrangência de escolas e educadores e realização de oficinas.

\section{Parâmetros para a FormaÇão Continuada de Atores do Sistema de Garantias dos Direitos da Criança e do Adolescente}

O Conselho Nacional dos Direitos da Criança e do Adolescente CONANDA -, (Resolução n. 112, de 27/03/06), traçou parâmetros consistentes acerca do processo de formação continuada dos integrantes do Sistema de Garantia de Direitos em todos os níveis, tendo como elemento propulsor as observações finais do Comitê dos Direitos da Criança (01/10/04) sobre os principais entraves, dificuldades e orientações para o Brasil implementar a Convenção sobre os Direitos da Criança, que destacam a imprescindibilidade e urgência de um plano sistemático para formação e conscientização de profissionais que trabalham com e para crianças.

Nesse passo, os Parâmetros traçados pelo CONANDA apontam elementos que deverão ser observados e incorporados pelo Projeto Escola que Protege, com as devidas compatibilizações. O primeiro deles é definição da continuidade e a progressividade do processo formativo, sempre objetivando o aprofundamento dos conteúdos, respeitadas e incorporadas as realidades, especificidades e diversidades regionais, possibilitando uma visão crítica da realidade e contextualização político-sócio-econômico do fenômeno da violência, com o intuito de qualificar as intervenções dos educandos, não apenas para identificar e providenciar respostas para as variadas situações de violências, mas sobretudo para facultar a construção de uma consciência crítica e provocar o compromisso como a proteção integral das crianças e adolescentes. 


\section{Considerações Finais}

Conforme sinalizado no Resumo deste trabalho, considerando o quadro de violência a que estão submetidas crianças e adolescentes no Brasil o MEC propôs às Pró-Reitorias de Extensão uma parceria na estruturação e implementação do Projeto Escola que Protege. O objetivo deste trabalho foi apresentar o referido Projeto e a forma como ele se efetivou no município de Natal.

Trata-se, antes de tudo, de mobilizar e convocar a rede de ensino no sentido de sensibilizar também as escolas e demais entidades educacionais para uma questão que, conforme vimos no Relatório da ONU, afeta grande parcela da população. Educadores foram convocados a participarem do sistema de garantia dos Direitos da Criança e do Adolescente, a partir do conhecimento de vários aspectos a esse sistema relacionados e das principais modalidades de violência presentes no cotidiano de grande parcela da população infantil.

A condição peculiar de desenvolvimento das crianças reconhecida pelo ECA e a condição de dupla vulnerabilidade a que se encontram grande parcela da população infantil deveriam implicar em maior mobilização do Estado e da Sociedade Civil no sentido de garantia de proteção principalmente contra a violação de seus direitos, estabelecidos no referido Estatuto. O projeto Escola que Protege, portanto, soma-se às demais iniciativas nesta área e reflete a recomendação 101, do Relatório da ONU que afirma:

101. Recomendo que a capacidade de todas as pessoas que trabalham com e para crianças visando contribuir para eliminar todas as formas de violência contra elas seja desenvolvida. Uma capacitação inicial e em serviço que transmita conhecimentos e o respeito aos direitos da criança deve ser oferecida. Os Estados devem investir em programas educacionais e de capacitação sistemáticos para profissionais e leigos que trabalham com ou para crianças e famílias com vistas a prevenir, detectar e responder à violência contra crianças. Códigos de conduta e normas claras para práticas devem ser formuladas e implementadas, incorporando a proibição e a rejeição de todas as formas de violência. (ONU, 2006)

\section{Notas}

${ }^{1}$ Relatório do Estudo das Nações Unidas sobre a Violência Contra Crianças, coordenado por Paulo Sérgio Pinheiro, apresentado de acordo com a resolução 60/231 da Assembléia Geral. Esclarecemos que embora o relatório faça referência a apenas "crianças", quando das referências à faixa etária inclui crianças e adolescentes, de acordo com o ECA, ou seja, a população de zero a 18 anos de idade, incompletos. 
Um projeto de multiplicidade entre pesquisa, extensão, universidade e comunidade: vivenciando a cultura no bairro Restinga

\section{REFERÊNCIAS}

BRASIL. Ministério da Educação. Secretaria de Educação Continuada, Alfabetização e Diversidade (SECAD). Circular n ${ }^{\circ}$ 004/06CGAEC/DEDC/SECAD/ MEC. Brasília, DF, 03 abr. 2006.

CONANDA. Parâmetros para formação continuada de atores do sistema de garantias dos direitos da criança e do adolescente. Brasília, DF: Secretaria Especial dos Direitos Humanos, 2006.

FALEIROS, V. P; FALEIROS, E. T. S Formação de educadores (as): subsídios para atuar no enfrentamento à violência contra crianças e adolescentes. Brasília, DF: MEC/SECAD; Florianópolis: UFSC/SEaD, 2006.

FRANCISCHINI, R. As faces da infância em contextos de violência física intrafamiliar. Perfil, Assis, v. 15, p. 71-86, 2003.

MINAYO, M. C. de S. O desafio do conhecimento: pesquisa qualitativa em saúde. 7. ed. São Paulo: Hucitec; Rio de Janeiro: Abrasco, 2000. Vozes, 2001 .

(Org.). Pesquisa social: teoria, método e criatividade. 19. ed. Petrópolis:

ONU. Relatório sobre o estudo das Nações Unidas sobre a violência contra crianças. PINHEIRO, P. S. (Org.). [S.1.: s.n.], 2006.

Disponível em: <http://www.unviolencestudy.org>. Acesso em 13 dez. 2006.

Recebido em: setembro/2006

Aceito em: novembro/2007 
